\title{
Seismogram Analysis of C052198B Earthquake, Minahasa at Observatory Stations in Australia
}

\author{
Bagus Jaya Santosa \\ Physics Dept., FMIPA, ITS, \\ Jl Arif Rahman Hakim 1, Kampus ITS Sukolilo, Surabaya 60111, Indonesia \\ Email: bjs@physics.its.ac.id
}

\begin{abstract}
The earth structure between the Minahasa earthquake, coded as C052198B, and observatory stations in Australia has been investigated through analysis in the time domain of three-component seismograms. The synthetic seismograms are constructed from an earth model, the CMT solution of the earthquake and station locations. The calculation is based on the GEMINI method, and the corner frequency is set at $20 \mathrm{mHz}$. Using deconvolutions of the station instruments responses, the measured and synthetic seismogram can be compared with the same units. The seismogram comparison indicates discrepancies between recorded data and synthetic seismograms calculated from the anisotropic PREM model, in the travel times of Rayleigh and Love surface wave, as well as the $\mathrm{S}$ and core reflected $\mathrm{ScS}$ and $\mathrm{ScS}_{2}$ body waves. Discrepancies of Love wave travel time and the number of oscillations are explained by changes in the crustal velocity model and by setting the positive gradient of $\beta_{\mathrm{h}}$ in the upper mantle. While for Rayleigh waves and arrival times of body waves, corrections to the zero order coefficients of $\beta$ are needed at layers in the mantle. The interpretation of the results of the waveform analyses indicates strong anisotropy in the upper mantle. The anisotropy also occurs, to a lesser extent, at layers beneath the upper mantle.
\end{abstract}

Keywords: anisotropy; earth model; waveform analysis.

\section{$1 \quad$ Introduction}

The Celebes Island is a geological area with complex tectonics. In this area three continental plates collide, the Arafuru plate that was part of the Australian plate, the East Asia plate and the West South Pacific plate. This collision produces fault planes and mountains on Celebes Island. The ocean plates move with a speed of approximately $8 \mathrm{~cm} / \mathrm{year}$. The collision between the plates in the Celebes area is marked by the occurrence of many earthquakes in this area. One earthquake occurred on May $21^{\text {st }} 1998$, in Minahasa, North Celebes, and is coded as C052198B. The seismogram data of this earthquake will be analyzed. Using sensitive seismometers installed in observatory stations, the ground movements due to the earthquake were recorded in Australia. The recorded data are converted from the ground velocity $[\mathrm{mm} / \mathrm{s}]$ to electrically digital data $[\mathrm{mV}]$.

Received December $9^{\text {th }}, 2009$, Revised June $17^{\text {th }}, 2010$, Accepted for publication March $16^{\text {th }}, 2012$.

Copyright (C) 2012 Published by LPPM ITB, ISSN: 1978-3043, DOI: 10.5614/itbj.sci.2012.44.1.7 
In the recording process, several devices are involved, that amplify and phase change the signal; the description of all the processes are documented in the response files of each observatory station.

The seismogram is a time series data that consists of complex wave phases, including the reflection/refraction that occurs due to structural layers of the Earth. The seismogram is constructed of various body wave phases and surface waves. The seismogram recording in an observatory station consists of several components. The types of seismogram data are the UL (Ultra Long Period), LP (Long Period), SP (Short Period) and Broad band, and the recording consists of three components, Z (vertical), N (North-South) and E (East-West). The main quantitative analysis of the seismogram is to note the arrival times of several wave phases, especially $\mathrm{P}$ waves, and the $\mathrm{S}$ and $\mathrm{P}$ amplitudes and polarities. The easiest measurement is the arrival times of $P$ waves, because the $P$ wave is the first break. The arrival time measurements are conducted using the SP and Broad-band data. The SKS/ SKKS travel times are also easy to measure, because SKS and SKKS are recorded with little interference with other seismic phases in a very broad distance interval. The other quantitative analyses of the seismograms that are conducted with the LP, SP and broad band data, are the dispersion analyses, by measuring the phase velocity of the surface wave as a function of the period/frequency. However the measured data in the dispersion analysis is a secondary data. Another method to determine the elastic parameters of the Earth is the Normal Mode method [1], which is suitable for the global spherical earth. However the frequencies that can be used are very low, $<8 \mathrm{mHz}$, therefore the UL data is used.

The first three quantitative methods that are used to analyze the seismogram above, only evaluate certain information in the seismogram time series. The research in this article used the seismogram comparison method between the measured and three component synthetic seismograms in the time domain, with frequencies as high as $40 \mathrm{mHz}$, which is 5 times higher than the frequencies in the Normal Mode method. The encountered problem in this research is, whether the earth models that are determined by processing a few pieces of information (arrival time, difference arrival times and dispersion analysis) in the seismograms, could result in synthetic seismograms which resemble the observed seismograms. The waveform analyses are carried out with a corner frequency of $20 \mathrm{mHz}$, because at the higher corner frequency the waveform comparison shows that the discrepancy is unsystematic. This method is one of the best in seismogram analyses, because all the information in the seismogram is analyzed, not only certain points in the seismogram.

Several seismological studies using arrival time data of the P and S waves, PP and Pdiff [2-7], also the dispersion data of the Rayleigh and Love surface wave 
[8-11] have been carried out in this area. In this article the structure of the Earth between the hypocenter of the C052198B earthquake, Minahasa and observatory stations in Australia will be retested. Whether obtained S wave anomalies are in accordance with the results of other seismogram analyses are studied through arrival time and dispersion analyses [12].

\section{Research Methodology}

The seismogram data have been downloaded from IRIS Data Center, using the Web page. The complex ground movement at a station will be recorded in the directions of the three Cartesian components (N-S, E-W and vertical Z, local in the position of the receiver station, is known as the recorder components with the suffix $-E,-N \&-Z$ ). The position of the earthquake source is in Minahasa, Indonesia with the coordinates $0.21^{\circ}$ North Latitude and $119.58^{\circ}$ East Longitude, $28 \mathrm{~km}$ depth, and magnitude of 6.2. The fault planes of the earthquake have strike $=108^{\circ}$, and $207^{\circ}$, dip $=64^{\circ}$, and $72^{\circ}$, and slip $=160^{\circ}$, and $28^{\circ}$, and scalar moment is $1.03 \mathrm{e}+26$ dyne-cm. The slip gives the motion of the hanging wall relative to the footwall. It is an angle from horizontal (in the given strike direction), increasing in a counter-clockwise sense, in the fault plane.

The position of the observatory stations and earthquake epicenter is presented in table 1. The path of the wave propagation from the earthquake epicenter to the position of the observatory stations is illustrated in Figure 1.

To identify the body wave phases in the seismogram, the ttimes program is used, which is based on the paper of Bulland and Chapman [13], downloaded from http://orfeus.knmi.nl. Figures $2-5$ display the original seismograms at each station for all components $(\mathrm{t}, \mathrm{r}, \mathrm{z})$ and marked arrival wave phases such as $\mathrm{P}, \mathrm{S}, \mathrm{SS}, \mathrm{ScS}, \mathrm{ScSn}$, Love and Rayleigh wave phases in the seismogram.

Table 1 The position of observatory stations used in this research according to http://www.fdsn.org/stations/FDSNstations.htm.

\begin{tabular}{cccc}
\hline No & Station & $\begin{array}{c}\text { South } \\
\text { Latitude }\end{array}$ & $\begin{array}{c}\text { East } \\
\text { Longitude }\end{array}$ \\
\hline 1 & WRAB & 19.93 & 134.36 \\
2 & CTAO & 20.09 & 146.25 \\
3 & NWAO & 32.93 & 117.23 \\
4 & CAN & 35.32 & 149.00 \\
\hline
\end{tabular}




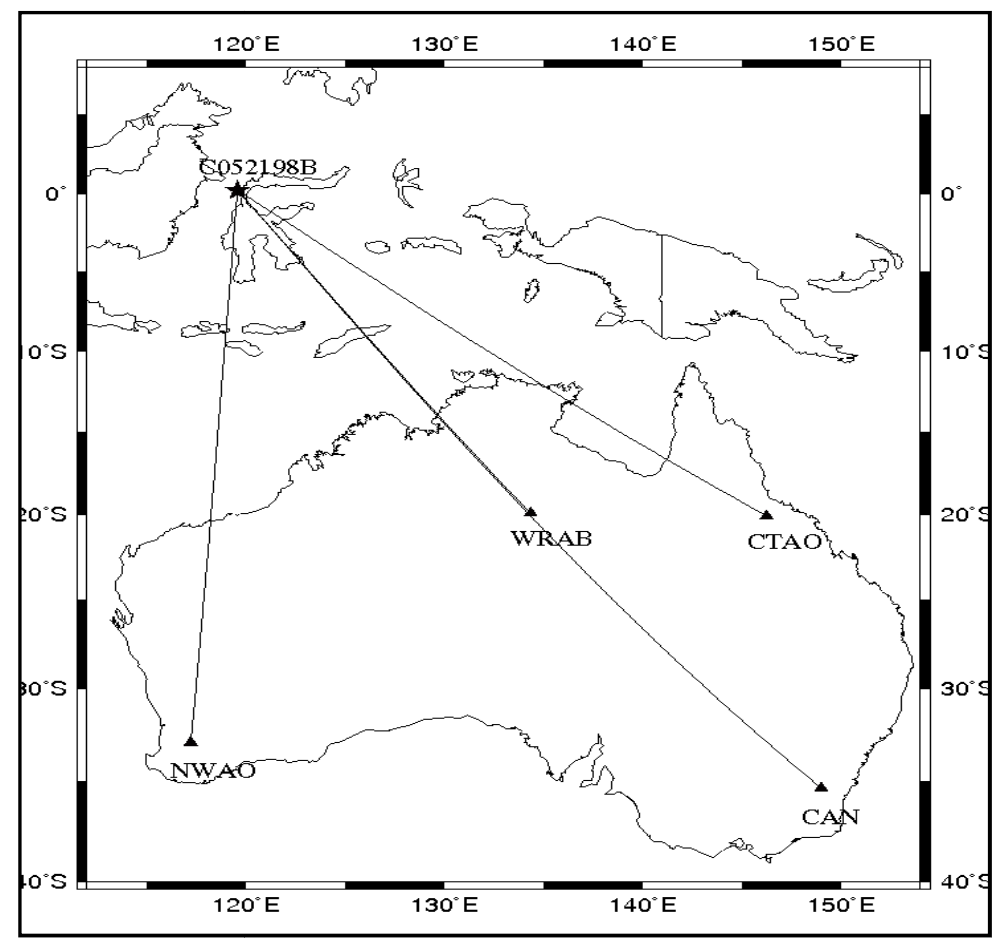

Figure 1 Vertical projection of released seismic wave paths from earthquake source to several observatory stations in Australia
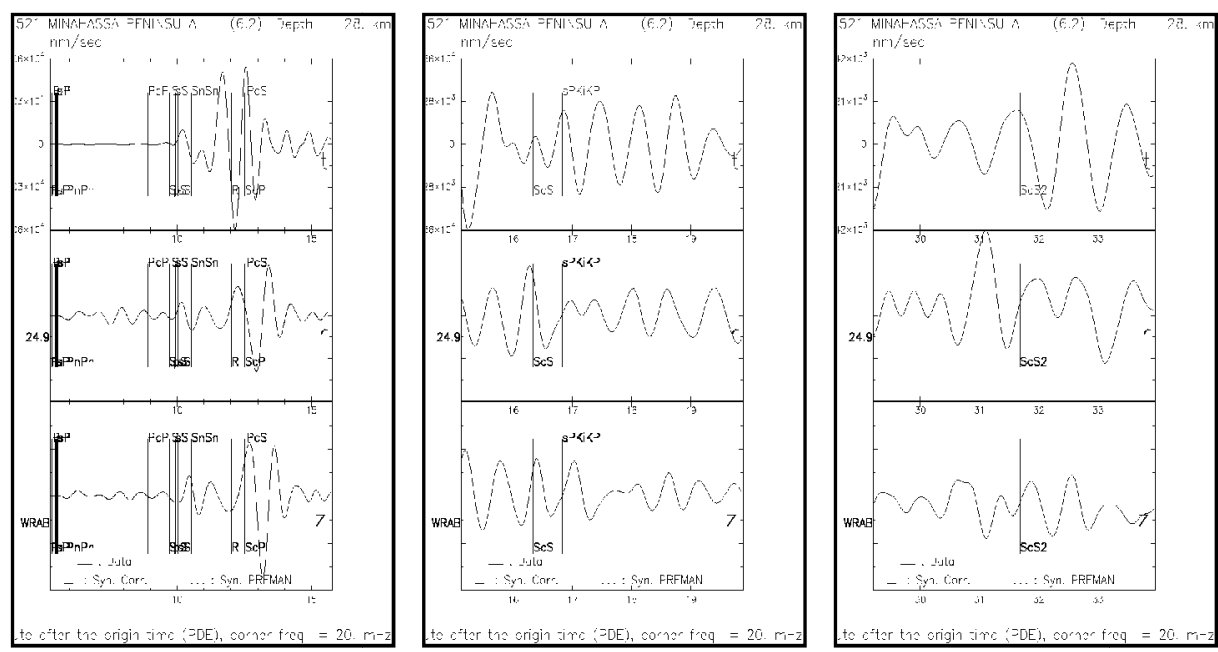

Figure 2 Seismogram data and wave phases using travel times at WRAB. 
To produce the synthetic seismogram from a global earth model [14] for a certain earthquake depth, the GEMINI method is used [15-17]. The GEMINI method is equivalent to the Normal Mode method, but the frequency limit can be chosen arbitrarily, where in this research the Nyquist frequency is set at 40 $\mathrm{mHz}$, and produced complete synthetic seismogram in the time domain and for the three Cartesian components. At higher frequencies the difference between observed and synthetic seismogram becomes unsystematic. The determination of the earthquake moment tensor using the time series data is carried out using a lower corner frequency, $8 \mathrm{mHz}$.

The response file of the seismometer instrument system at the receiver station for the various channels $(\mathrm{N}, \mathrm{E} \& \mathrm{Z})$ is used to deconvolve to the recorded seismogram (the units $\mathrm{mV}$ is changed into $\mathrm{mm} / \mathrm{s}$ ), so that the seismogram comparison between the observed and the synthetic waveforms is conducted with the same units $[\mathrm{mm} / \mathrm{s}]$.

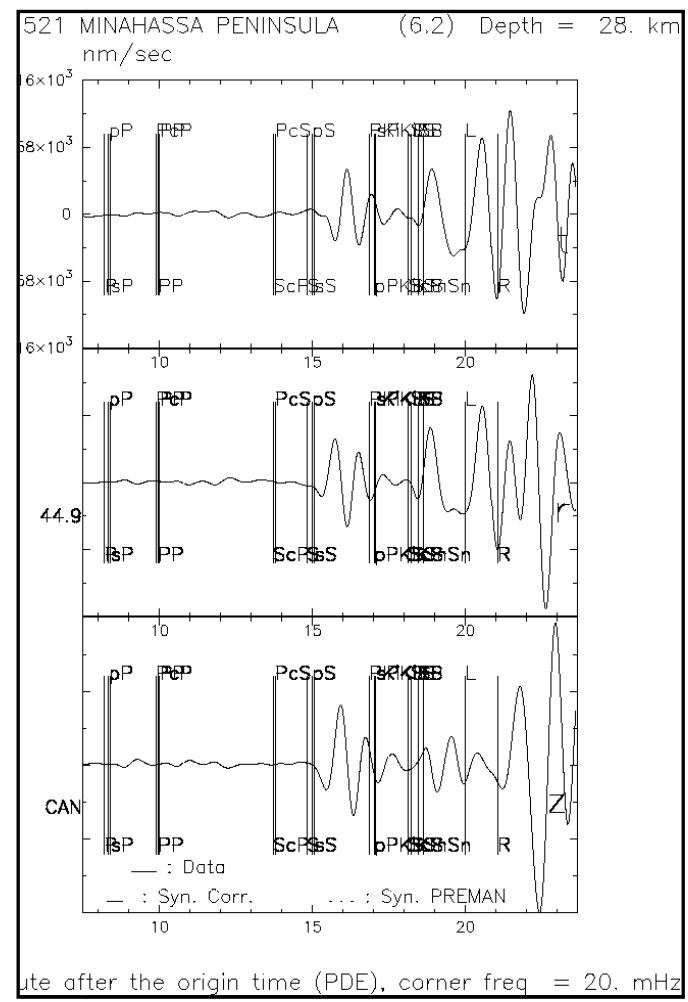

Figure 3 Seismogram data and wave phases using travel times at CAN. 


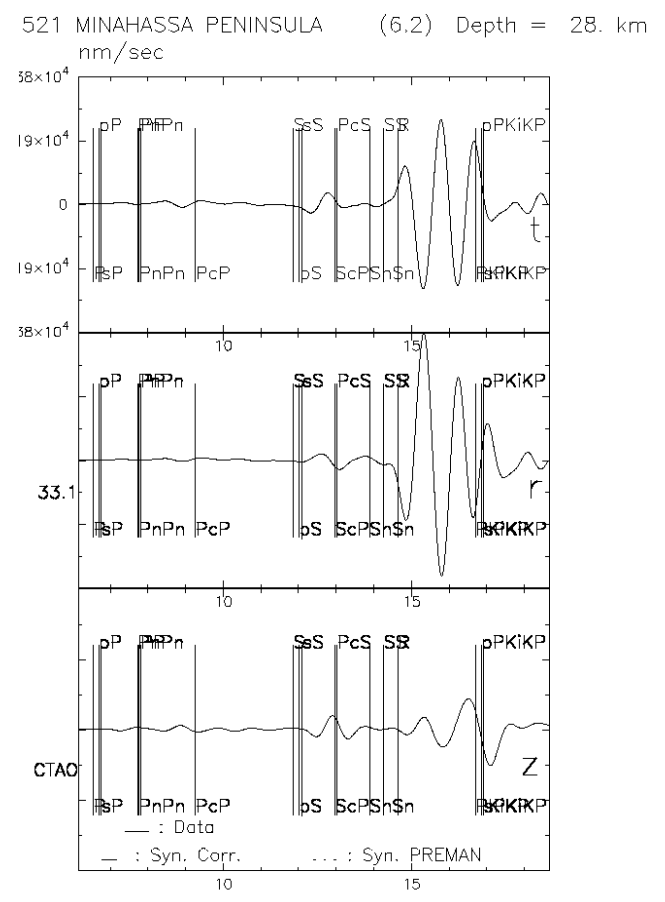

the after the origin time (PDE), corner freq $=20 . \mathrm{mHz}$

Figure 4 Seismogram data and wave phases using travel times at CTAO.
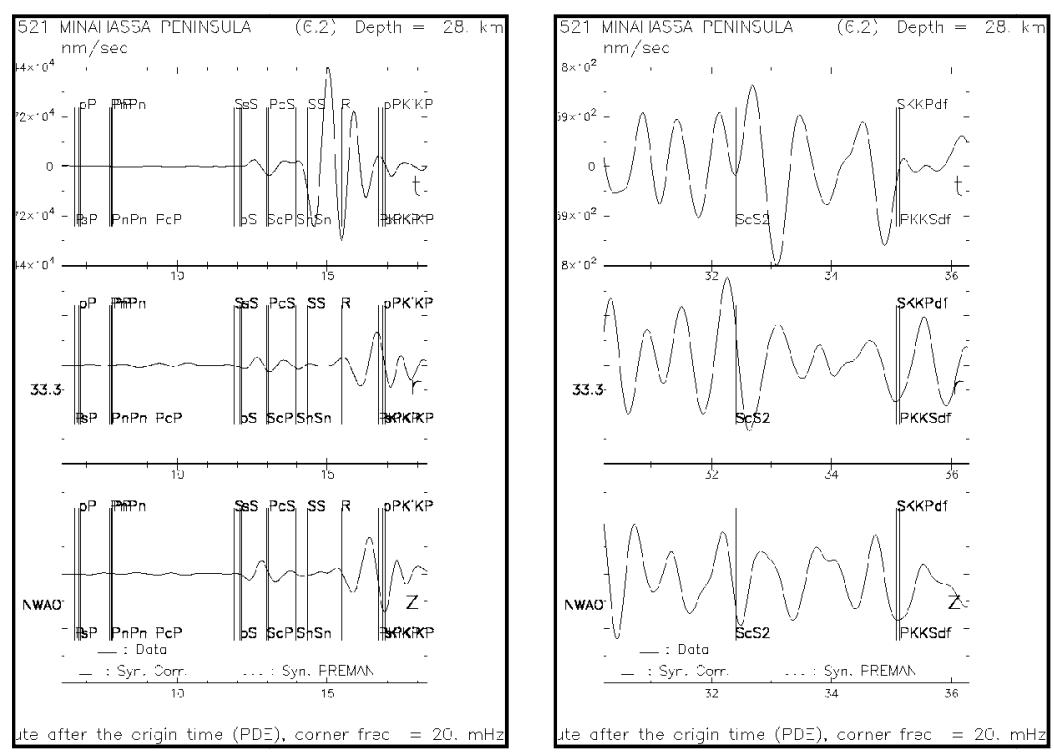

Figure 5 Seismogram data and wave phases using travel times at NWAO. 


\section{Seismogram Analyses and Discussion}

Each figure in the following presents 3 curves which show the ground movements in three components. The recorded seismogram is a solid line, the synthetic seismogram constructed from the global vertical anisotropic PREM (PREMAN hereafter) earth model is a dotted curve, and synthetic from the corrected earth model is a dashed-line curve. Each trace express the ground movement in the Cartesian components which are $z$ (vertical), $r$ (radial) and $t$ (transverse). The small box at the right of Figures 6 - 9 shows the S velocity structure between the earthquake source and the station.

The first one presented is the seismogram comparison for the WRAB station, which is located in northern Australia. Figure 6 shows an excellent fit not only to the Rayleigh and Love surface waves, but also to S and SS body waves. The fit is obtained by increasing the earth crust thickness by $4 \mathrm{~km}$ compared to the PREMAN earth model and changing the velocity gradient of $\beta_{\mathrm{h}}$ in the earth upper mantle to positive, and small positive corrections to the zero order coefficients of the polynomial function, which express the $\beta$ wave velocity in the mantle layers, from the upper mantle down to $771 \mathrm{~km}$ depth. The positive correction should be imposed on all mantle layers, because all the wave phases given by the synthetic from the PREMAN earth model arrive later than the measured wave phases. In this small epicentral distance which is $24.9^{\circ}$, the delay of the Love main oscillation is 25 seconds, whereas the delay of the $\mathrm{S}$ wave is 14 seconds, a big arrival time difference. This indicates that the anisotropy is stronger than stated in other seismological research $[18,19]$. Figures $6 \mathrm{~b}$ and $6 \mathrm{c}$ shows arrival time fits of $\mathrm{ScS}$ and $\mathrm{ScS}_{2}$ from core reflected $\mathrm{S}$ body waves. The change in the crustal thickness influences the amplitude of the core reflected waves and is not well known by other seismologists, because they analyze only the arrival time differences of $\mathrm{S}$ and $\mathrm{ScS}$ waves or $\mathrm{ScS}_{\mathrm{n}}$ $\mathrm{ScS}_{\mathrm{j}}$, where the time arrival measurement is conducted at stations with epicentral distances over $45^{\circ}$ [19]. The ScS and multiple core reflected waves can be seen clearly on the t component, because the Core Mantle Boundary is a good $\mathrm{S}$ wave reflector; the differences in the waveform fitting in the $t$ and $r$ components show that the anisotropy at the base of the mantle is stronger than stated in other seismological research [20,21]. Besides, waveform analyses of core reflected waves using small epicentral distances give a new road for study of the $\mathrm{S}$ wave velocity structure in all mantle layers, which is better than the arrival time difference method. The ttimes program provides only the travel time of $\mathrm{ScS}$ wave, no multiple wave phases, as illustrated in Figure 6d. Although the travel time is labeled with PKKPdf, the waveform is not this wave phase, but the multiple core reflected $\mathrm{ScS}_{2}$ wave phase, because the travel times of multiple $\mathrm{ScS}_{\mathrm{n}}$ can be estimated as integer multiplications of the $\mathrm{ScS}$ arrival times, by observing large amplitudes on the transversal component. 

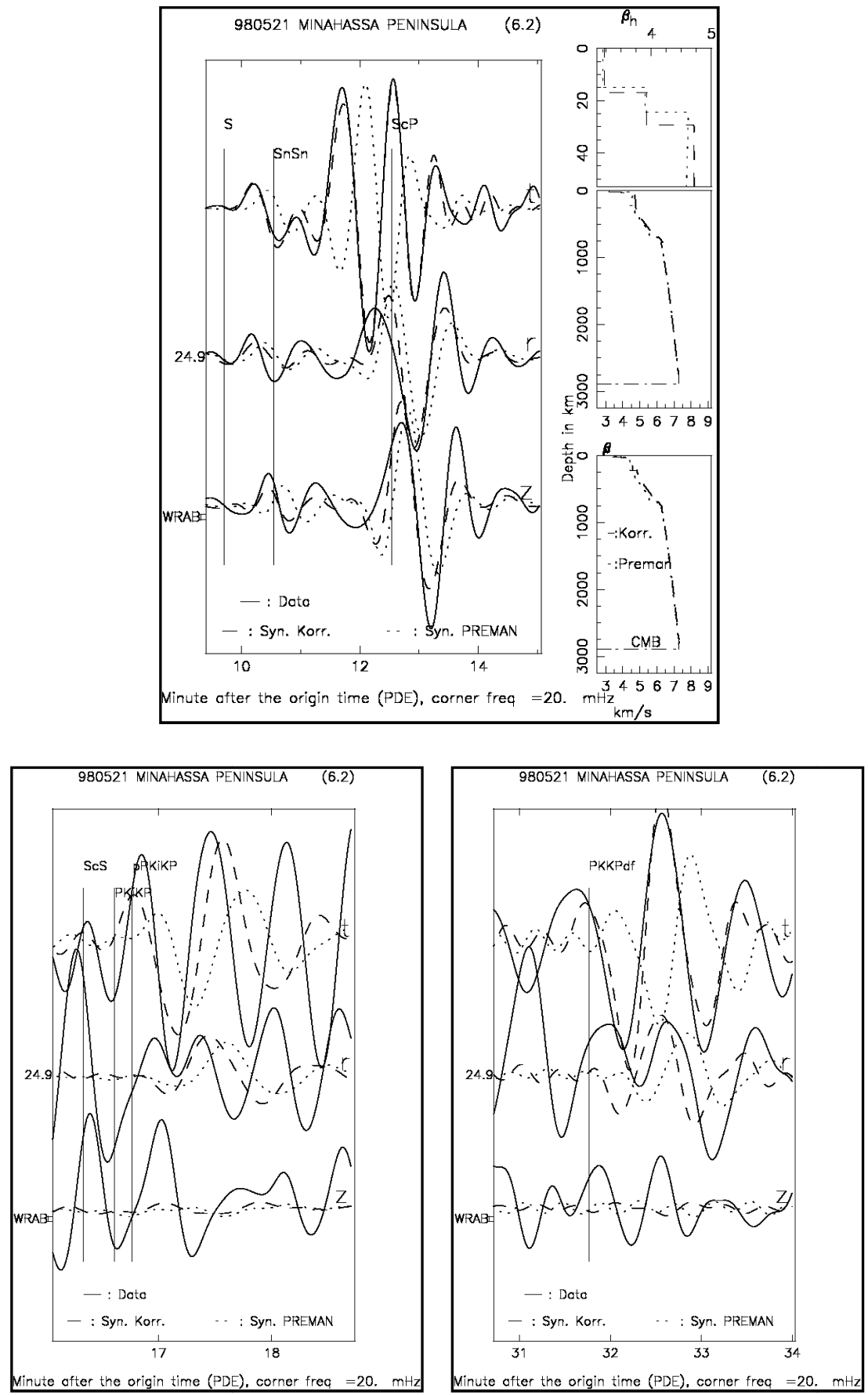

Figure 6 Seismogram comparison at WRAB station, a). S, SS, L and R; b). ScS and c). $\mathrm{ScS}_{2}$ waves. 


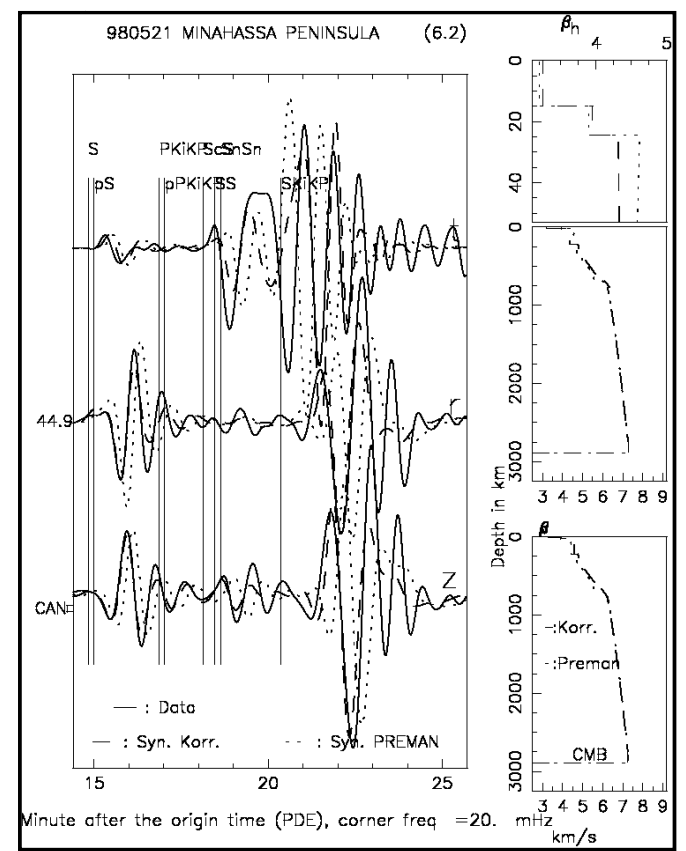

Figure 7 Seismogram comparison at CAN station, S, SS, L and R waves.

Figure 7 presents the seismogram comparison between the recorded and the synthetic seismograms which are constructed from PREMAN and the corrected earth model for the CAN station. The comparison using the PREMAN earth model shows that arrival time delays occur in all body wave phases and surface waves in the $z$ and $r$ (P-SV) components. The delay of the Rayleigh waves reaches 28 seconds, and 8 seconds for the $\mathrm{S}$ wave. A correction must be imposed for all layers to $771 \mathrm{~km}$ depth, and this shows that anisotropy occurs also in the mantle layers below the upper mantle. This strong delay indicates that the subduction zone in South Indonesia has a positive anomaly in S wave propagation. The anisotropy in the mantle is also observed using SKS wave splitting at stations with epicentral distances over $60^{\circ}[22,23]$. SKS and SKKS are recorded free from interference with other seismic phases in a very broad distance interval, which makes them observable at any sufficiently sensitive seismic station equipped with medium period seismographs, but they measured only the travel time difference of SKS in the $r$ and $t$ components. This research analyzed the complete seismogram in time domain and three components simultaneously. Observations on the $t$ component show conversely, that the big oscillations from the Love wave arrive 24 seconds earlier. Anisotropy is stronger than the supposed anisotropy in upper mantle layer of the PREMAN Earth model. For the synthetic seismograms, the data could be matched only on the beginning phase from the SS wave, and beginning and end part of the signal 
between the SS and Love waves. The wave paths from the earthquake epicenter to the two observatory stations of WRAB and CAN are very close to each other. We can see that there is a discrepancy in the SV and SH arrival times and both types of surface wave have a different deviation. This indicates that strong anisotropy occurs not only in the upper mantle, but also in the deeper mantle layers with weaker anisotropy.

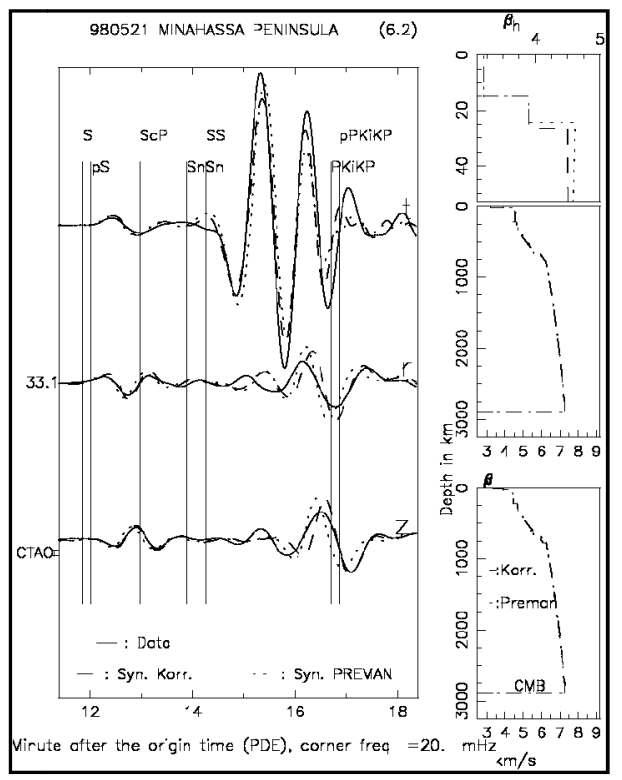

Figure 8 Seismogram comparison at CTAO station, S, SS, L and R waves.

Figure 8 shows the seismogram comparison at the CTAO station, which is located in Queensland, Australia. Compared to the WRAB station, the location of the CTAO station is in eastern Australia, and the wave path is dominated by Australian continent crust. The thickness of the crust is only $2 \mathrm{~km}$ thicker than the PREMAN model. Differences for the arrival times of the synthetic Love and Rayleigh waves from the PREMAN model are small. This indicates that the upper mantle between the earthquake hypocenter and the station has weaker anisotropy than in the PREMAN model.

The seismogram comparison between the recorded and the synthetic waveforms from PREMAN and the corrected Earth model are illustrated in Figure 9. To obtain the fit to this seismogram, the change in the $\mathrm{S}$ wave velocity structure is carried out in the values of the zero order coefficients of the $\beta$ polynomial function. From the theory of elasticity in a homogeneous medium it is known 
that $\quad-$ and $\quad-$, where $\lambda$ and $\mu$ are Lame parameters, and $\rho$ is rock density, so the change in $\beta$ also influences the $\mathrm{P}$ wave simulation, as can be seen in Figure 9a. Figure 9b shows the fit to the $\mathrm{S}$ wave, as well as the Love and
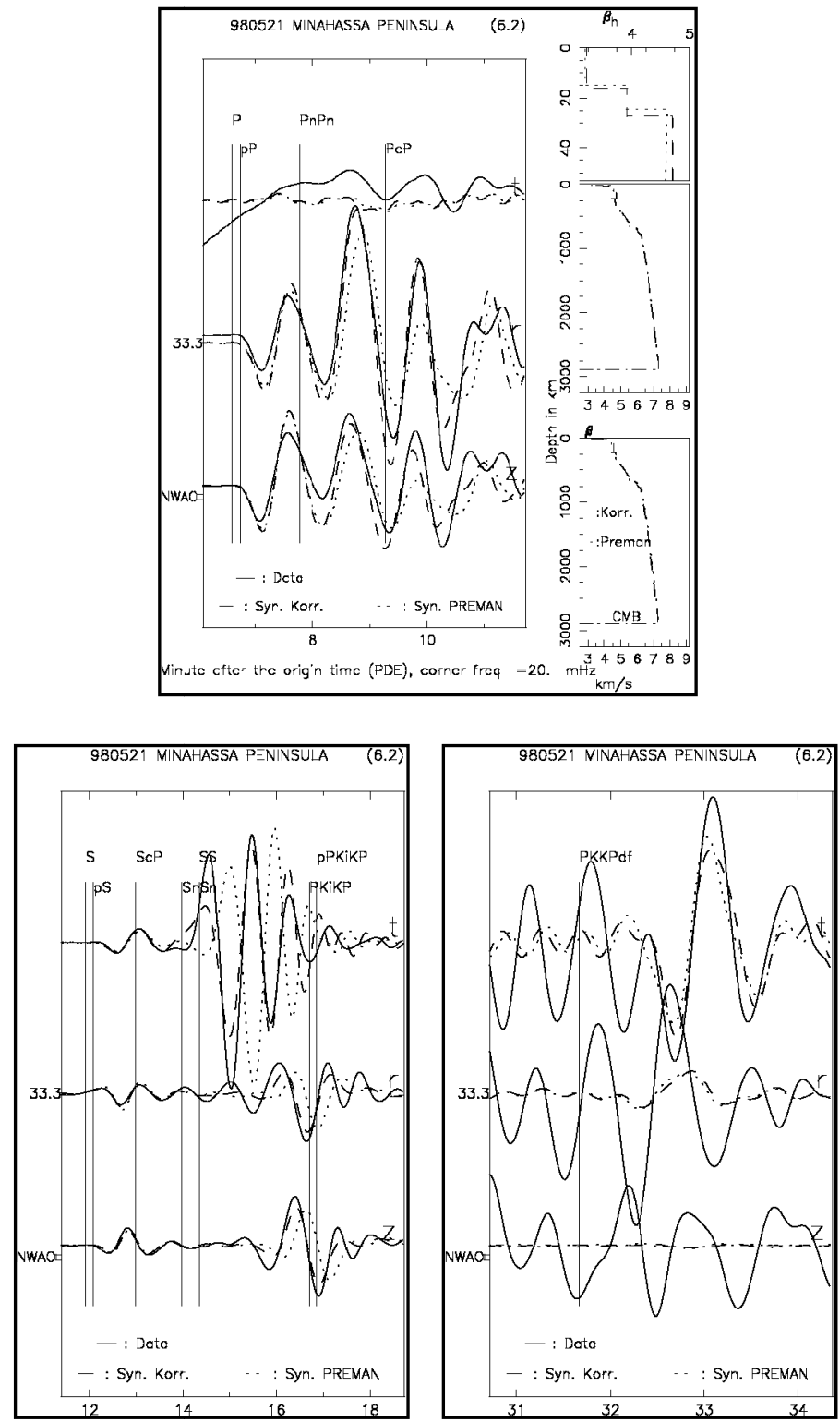

Figure 9 Seismogram comparison at NWAO station, a. P; b. S, L and R and c. $\mathrm{ScS}_{2}$ waves. 
Rayleigh surface waves. Comparison to observations shows that the synthetic Rayleigh wave from PREMAN arrives 14 seconds later than the recorded Rayleigh wave, whereas synthetic Love waves arrive 29 seconds later. This shows that anisotropy in the upper mantle and deeper layers are stronger than supposed in the PREMAN model $[8,9,21]$. The $\beta$ wave velocity has been changed from the upper mantle down to $771 \mathrm{~km}$ depth providing a fit of the $\mathrm{ScS}_{2}$ wave phase, as pointed out in Figure 9c.

From other previous studies, the seismic anisotropy can be probed using a variety tools, including shear-wave splitting of core-refracted phases (SKS and SKKS). This research analyzed the travel times of core phases on three components [21,22] and anisotropic receiver function [24], but the receiver function method still used an isotropic earth model.

\section{Conclusions}

The S wave velocity structure between Minahasa and observatory stations in Australia has been investigated through seismogram analysis of the C052198B Minahasa earthquake, using three-component time domain data. The analyses showed that the discrepancies between the recorded and the synthetic seismograms, which are constructed from the PREMAN model, not only occurred in the arrival times of the Rayleigh and Love surface waves, but also in the $\mathrm{S}$ body waves and the core reflected $\mathrm{ScS}$ and $\mathrm{ScS}_{2}$ waves. The discrepancy of the Love waves is observed in the travel times and the number of oscillations. These waveform discrepancies were explained by changing crustal thickness and imposing a positive gradient of $\beta_{\mathrm{h}}$ in the upper mantle layers. For matching the arrival times of the body waves, corrections in $\beta$ velocities of the deeper mantle layers are required. These results of the interpretation on the seismogram analyses showed that there is strong anisotropy in the upper mantle, and weaker anisotropy in the deeper mantle layers. From observing the core reflected waves, $\mathrm{ScS}$ and $\mathrm{ScS}_{2}$, the anisotropy continues until the base of the mantle.

\section{References}

[1] Pekeris, C. L. \& Jarosh, H., The Free Oscillations of The Earth in Contributions in Geophysics, International Serial Monograph $\sim$ Earth Science, I, 171, Pergamon Press, 1958.

[2] Hafkenscheid, E., Buiter and S.J.H., Wortel, M.J.R. Modeling the Three Dimensional Seismic Velocity Structure below Indonesia: A Comparison With Tomography, Tectonophysics, 333, pp. 35-46, 2001.

[3] Gorbatov, A., Fukao, Y. \& Widiyantoro, S., Application of A Three Dimensional Ray-Tracing Technique to Global P, PP and Pdiff Travel 
Time Tomography, Geophysical Journal International, 146, pp. 583-593, 2000.

[4] Li, C., Van der Hillst R.D. \& Toksoz, N.M., Constraining Spatial Variations in P-Wave Velocity in The Upper Mantle Beneath SE Asia, Physics of the Earth and Planetary Interiors, 154, pp. 180-195, 2006.

[5] Latorre, D., Virieux, J., Monfret, T. \& Lyon-Caen, H., Converted Seismic Wave Investigation in The Gulf of Corinth from Local Earthquake, Comp. Rendus Geoscience, 336, pp. 259-267, 2004.

[6] Sylvander, M., Monod, B., Souriau, A. \& Rigo, A., Analyse D'un Essaim De Sismicité (Mai 2004) Dans Les Pyrénées Orientales: Vers Une Nouvelle Interprétation Tectonique Du Séisme De Saint-Paul-DeFenoulliet (1996), Comp. Rendus Geoscience, 339, pp. 75-84, 2007.

[7] Olsson, S., Roberts, R.G. \& Böðvarsson, R., Analysis of Waves Converted From $S$ to $P$ in The Upper Mantle Beneath The Baltic Shield, Earth and Plan. Sci. Letters, 257, pp. 37-46, 2007.

[8] Simons, F.J., van der Hillst, R.D., Montagner, J.P. \& Zielhuis, A., Multimode Rayleigh Inversion for Shear Wave Speed Heterogeneity and Azimuthal Anisotropy of The Australian Upper Mantle, Geophysical Journal International, 151, pp. 738-754, 2002.

[9] Debayle, E., Kennett, B. \& Priestley, K., Global Upper Mantle Azimuthal Anisotropy and The Peculiar Behavior of The Australian Plate, America Geophysical Union 2004 Meeting (http://www.agu.org/meetings/tm04/ fm04\sessions/fm04\T31D.html)

[10] Nishimura, T., Yoshimoto, K., Ohtaki, T., Kanjo, K. \& Purwana, I., Spatial Distribution of Lateral Heterogeneity in The Upper Mantle Around The Western Pacific Region as Inferred from Analysis of Transverse Components of Teleseismic P-Coda, Geophysical Research Letter, 29(23), pp. 2137-2154, 2002. doi: 10.1029/2002GL015606.

[11] Zhang, X., Paulssen, H., Lebedev, S., Meier, T., 3D Shear Velocity Structure Beneath The Gulf of California from Rayleigh Wave Dispersion, Earth and Plan. Sci. Letters, 279, pp. 255-262, 2009.

[12] Badal, J., Chen, Y. \& Zhang, Z., Modeling of Rayleigh Wave Dispersion In Iberia, Geoscience Frontiers, 2, pp. 35-48, 2011.

[13] Bulland, R. \& Chapman, C. Travel Time Calculation, Bulletin Seismological Society of America, 73, pp. 1271-1302, 1983.

[14] Dziewonski, A.M. \& Anderson, D.L., Preliminary Reference Earth Model, Physics of the Earth and Planetary Interior, 25, pp. 297-356, 1981.

[15] Dalkolmo, J., Synthetische Seismogramme Für Eine Sphärisch Symmetrische, Nichtrotierend Erde Durch Direkte Berechnung Der Greenschen Funktion, Diplomarbeit, Institut für Geophysik, Universität Stuttgart, 1993.

[16] Friederich, W. \& Dalkolmo, J., Complete Synthetic Seismograms for A Spherically Symmetric Earth by A Numerical Computation of The 
Green's Function in The Frequency Domain, Geophysical Journal International, 122, pp. 537-550, 1995.

[17] Bagus, J.S., Möglichkeiten und Grenzen der Modellierung vollständiger langperiodischer Seismogramme, Doktorarbeit, Berichte Nr. 12, Institut für Geophysik, Uni. Stuttgart, 1999.

[18] Souriau, A. \& Poupinet, G., A Study of The Outermost Liquid Core Using Differential Travel Times of The SKS, SKKS and S3KS Phases, Physics of the Earth and Planetary Interior, 68(1-2), pp. 183-199, 1991.

[19] Debayle, E. \& Lèvěque, J.J., Upper Mantle Heterogeneities in The Indian Ocean from Waveform Inversion, Geophysical Research Letter, 24, pp. 245-248, 1997.

[20] Wysession, M.E., Valenzuela, R.W., Zhu, A. \& Bartkö, L., Investigating the Base of The Mantle Using Differential Travel Times, Physics of the Earth and Planetary Interior, 92(1-2), pp. 67-84, 1995.

[21] Tong, C., Gudmundsson, O. \& Kennett, B.L.M., Shear Wave Splitting in Refracted Waves Returned from The Upper Mantle Transition Zone Beneath Northern Australia, Journal of Geophysical Research, 99, B8, 15,783-15,797, 1994.

[22] Vinnik, L.P., Kind, R., Kosarev, G.L., Makeyeva, L.I. Azimuthal Anisotropy in the Lithosphere from Observation of Long-Period S-Wave, Geophys. J. Int, 99, pp. 549-559, 1989.

[23] Bai, L., Iidaka, T., Kawakatsu, H., Morita, Y. \& Dzung, N.Q., Upper Mantle Anisotropy Beneath Indochina Block and Adjacent Region from Shear-Wave Splitting Analysis of Vietnam Broadband Seismograph Array Data, Phys. Earth Planet. Inter, 162, pp. 73-84, 2009.

[24] Levin, V. \& Park, J., P-SH Conversions in Layered Media with Hexagonally Symmetric Anisotropy: A Cookbook, Pure Appl. Geophys, 141, pp. 669-697, 1998. 